\title{
Streptococcus anginosus group infection as a predictor for the progression of descending necrotizing mediastinitis
}

\author{
Takashi Sakai^, Atsushi Sano, Yoko Azuma, Satoshi Koezuka, Hajime Otsuka, Akira Iyoda \\ Division of Chest Surgery, Department of Surgery, Toho University School of Medicine, Tokyo, Japan \\ Contributions: (I) Conception and design: All authors; (II) Administrative support: A Iyoda; (III) Provision of study materials or patients: All authors; \\ (IV) Collection and assembly of data: T Sakai, A Sano; (V) Data analysis and interpretation: T Sakai, A Sano; (VI) Manuscript writing: All authors; (VII) \\ Final approval of manuscript: All authors. \\ Correspondence to: Akira Iyoda, MD, PhD. Toho University School of Medicine, 6-11-1, Omorinishi, Ota, Tokyo 143-8541, Japan. \\ Email: aiyoda@med.toho-u.ac.jp.
}

\begin{abstract}
Background: The prognosis of descending necrotizing mediastinitis (DNM), especially that extending inferiorly to the carina, remains poor. The identification of additional prognostic factors may improve the prognosis.
\end{abstract}

Methods: We retrospectively analyzed six patients who underwent thoracic surgery for DNM extending to the anterior and posterior mediastinum inferior to the carina (Endo classification type IIB) from 2014 to 2020. We reviewed their characteristics, clinical course, causative bacteria, and treatment to investigate their prognostic factors.

Results: The median patient age was 62 years. Five patients were men and one patient was a woman. The causative disease in three of the patients was pharyngolaryngeal, and for the others, it was an odontogenic infection. Five patients had sepsis and four had disseminated intravascular coagulation (DIC) at surgery. Four patients had polymicrobial infections of aerobic and anaerobic bacteria, all of whom showed gas bubbles on a chest computed tomography scan and detection of Streptococcus anginosus group (SAG). All patients underwent cervicotomy, tracheostomy, and mediastinal drainage and debridement via a transthoracic approach. Three patients underwent additional surgery or drainage because an additional abscess appeared postoperatively. The median duration of hospitalization was 58 days and the mixed infections, including SAG, were all detected in the three cases of long-term hospitalization. No disease-associated death was observed during the follow-up period of 18 months.

Conclusions: Mixed infection, including SAG, may be a predictor for DNM aggravation and spread. Gas bubbles on a chest computed tomography scan suggest polymicrobial aerobic and anaerobic infections including SAG, which require broad-spectrum antibiotic therapy and aggressive drainage and surgery.

Keywords: Descending necrotizing mediastinitis (DNM); Endo classification; Streptococcus anginosus group

Submitted Oct 26, 2020. Accepted for publication Jan 29, 2021.

doi: 10.21037/apm-20-2120

View this article at: http://dx.doi.org/10.21037/apm-20-2120

$\wedge$ ORCID: 0000-0003-2724-530X. 


\section{Introduction}

Descending necrotizing mediastinitis (DNM) is defined as a mediastinal infection arising from the oral, pharyngeal, and cervical area (1). As the infected area expands through the deep cervical fascial planes to the mediastinum and the general patient condition deteriorates rapidly with sepsis and multiple organ failure, the reported mortality for DNM in the 1900 s was as high as $23 \%$ to $36 \%$ (2). The recent development of antibiotics, the diagnostic accuracy of computed tomography (CT) scan, and intensive care may improve the mortality rate; however, more recent reported mortality rates remain as high as $17.5 \%(3,4)$. DNM is, therefore, still a life-threatening disease.

Successful treatment of DNM depends on early diagnosis, the administration of adequate antibiotics, and above all, aggressive and proper drainage (5-8). Endo et al. classified DNM according to three types depending on the anatomical extent of infection diagnosed by CT scan and recommended management according to each type (9). If the extent of the infection was localized to the upper mediastinal area above the carina (Endo classification: type I), cervical and transcervical mediastinal drainage may be used for the treatment of DNM. However, DNM extending to the mediastinum inferior to the carina (Endo classification: type II), which is defined as diffuse DNM, requires aggressive surgery, including radical surgery with drainage, pleurotomy, and debridement through a subxiphoid incision or thoracotomy $(6,8)$. The approach to the mediastinal cavity should be considered according to the extent of the infection. Some facilities reported the efficiency of the subxiphoid approach and video-assisted thoracic surgery (VATS) $(10,11)$. As insufficient drainage causes uncontrolled infection and poor prognosis, MartyAne et al. recommended aggressive surgical drainage via thoracotomy regardless of the extent of infection (6). Although the surgical approach and method according to the extent remains a controversial issue, early aggressive and sufficient drainage and intensive postoperative monitoring have become common practice $(3,12)$.

Although the treatment strategy has been recently formulated, the prognosis of DNM (especially diffuse DNM) remains poor. The reported predictors of mortality of DNM include Endo classification, comorbidity, and complication of sepsis (3). We present six cases of DNM at our institution and further analyze the bacterial features along with the reported predictors of DNM morbidity and mortality stated previously.
We present the following article in accordance with the STROBE reporting checklist (available at http://dx.doi. org/10.21037/apm-20-2120).

\section{Methods}

\section{Patients}

We retrospectively reviewed the medical database of Toho University Omori Medical Center and extracted the patients who underwent surgery for DNM in the division of Chest Surgery, Department of Surgery between January 2014 and March 2020. The study was conducted in accordance with the Declaration of Helsinki (as revised in 2013). The study was approved by institutional ethics board of Toho University Omori Medical Center (No. M19218) and individual consent for this retrospective analysis was waived. The extracted data were the patient's sex, age, smoking status, past history, causative disease and bacteria, image findings, treatment, and prognosis.

\section{Classifications and criteria}

We classified DNM according to the Endo classification (9), in which infection localized to the upper mediastinum area above the carina was classified as Type I, that extending to the lower anterior mediastinum as Type IIA, and that extending to the lower anterior and posterior mediastinum as Type IIB.

The definitions of systemic inflammatory response syndrome (SIRS) and disseminated intravascular coagulation (DIC) were based on the criteria from the Society of Critical Care Medicine and American College of Chest Physicians, and the Research Committee on DIC in Japan (13-15). Sepsis, septic shock, and sequential organ failure assessment (SOFA) scores were based on the criteria from the European Society of Intensive Care Medicine and the Society of Critical Care Medicine (16,17).

\section{Treatment strategy}

Multi-disciplinary discussions including an otolaryngologist, a dental and oral surgeon, an anesthesiologist, an infectious disease expert, and an emergency clinician were performed to decide the treatment plan. Critical care was performed in the intensive care unit in all cases. Drainage of the causative region of the oral, pharyngeal, or cervical area was done by the respective specialist and a tracheotomy was performed if the abscess impaired patient breathing. 
Table 1 Patients' characteristics

\begin{tabular}{|c|c|}
\hline $\begin{array}{l}\text { Characteristics } \\
(\mathrm{n}=6)\end{array}$ & $\begin{array}{l}\text { Median or number } \\
\text { [range or \%] }\end{array}$ \\
\hline Age (years) & 62 [48-84] \\
\hline Male & $5[83]$ \\
\hline Smoker & $5[83]$ \\
\hline Body mass index & 21 [18-25] \\
\hline \multicolumn{2}{|l|}{ Comorbidity } \\
\hline Chronic kidney disease & $2[33]$ \\
\hline Mental illness & $2[33]$ \\
\hline Diabetes mellitus & $1[17]$ \\
\hline Cirrhosis & $1[17]$ \\
\hline \multicolumn{2}{|l|}{ Infection site } \\
\hline Odontogenic infection & $3[50]$ \\
\hline Pharyngolaryngeal infection & $3[50]$ \\
\hline \multicolumn{2}{|l|}{ Causative bacteria } \\
\hline \multicolumn{2}{|l|}{ Aerobic bacteria } \\
\hline Streptococcus anginosus group & $4[67]$ \\
\hline Corynebacterium & $2[33]$ \\
\hline Streptococcus spp. & $1[17]$ \\
\hline \multicolumn{2}{|l|}{ Anaerobic bacteria } \\
\hline Prevotella & $2[33]$ \\
\hline Others & $2[33]$ \\
\hline Candida & $3[50]$ \\
\hline $\begin{array}{l}\text { Polymicrobial aerobic and anaerobic } \\
\text { infection }\end{array}$ & $4[67]$ \\
\hline Thoracic fluid collection & $4[67]$ \\
\hline Unilateral & $1[17]$ \\
\hline Bilateral & $5[83]$ \\
\hline Gas bubbles on the $\mathrm{CT}^{\dagger}$ scan & $4[67]$ \\
\hline Complaint with $\mathrm{DIC}^{\ddagger}$ & $4[67]$ \\
\hline Complaint with sepsis & $5[83]$ \\
\hline
\end{tabular}

${ }^{\dagger} \mathrm{CT}$, computed tomography; ${ }^{\ddagger} \mathrm{DIC}$, disseminated intravascular coagulation.

In the case of diffuse DNM, pleurotomy, debridement, and irrigation were performed for anterior, posterior, superior, and inferior mediastinal spaces, and three drainage tubes in total were inserted in the anterior, posterior, and on the diaphragm of the thoracic space. If pleural effusion was detected on CT scan, intrathoracic debridement and irrigation were performed. All thoracotomy procedures were performed using the two-port approach with a $15 \mathrm{~cm}$ and $1.2 \mathrm{~cm}$ wound. Follow up CTs were performed when necessary and recurrent drainage performed in three cases.

\section{Statistical analysis}

We only compared and considered the clinical factors and did not perform specific statistical analysis methods including $t$-test, chi-square test, and descriptive analysis, because the number of patients were small.

\section{Results}

\section{Patient characteristics}

Table 1 shows the patients' characteristics. There were six patients who underwent thoracic surgery for type IIB DNM (diffuse DNM) during the period. The median age was 62 years (range, $48-84$ years); 5 patients (83\%) were both male and smokers and one patient was a non-smoker woman. The median body mass index was $21 \mathrm{~kg} / \mathrm{m}^{2}$ (range, $18-25 \mathrm{~kg} / \mathrm{m}^{2}$ ). Two patients $(33 \%)$ had chronic kidney disease and mental illness and 1 patient (17\%) had diabetes mellitus and cirrhosis. No patients were taking glucocorticoids. Odontogenic infection was detected as the causative disease in three patients, including dental decay in two patients, and mandibular inflammation associated with osteonecrosis in one patient. Pharyngolaryngeal infection was detected as the causative disease in the other three patients. The causative bacteria were detected in 5 patients $(83 \%)$ and polymicrobial infection with aerobic and anaerobic bacteria including Streptococcus anginosus group (SAG) in four patients (67\%).

\section{Analysis of the treatment and outcomes}

Table 2 shows the detailed characteristics and treatment of the patients. The median duration from symptom onset was 13 days (range, 2-22 days). All patients received antibiotics from the time of hospitalization. Sulbactam and ampicillin were selected as the initial antibiotic agents in two patients, while carbapenem was selected for the other four patients. Cervicotomy, tracheotomy, and thoracotomy were performed in all patients. In thoracotomy, all patients underwent pleurotomy of all the mediastinal pleura, debridement of the mediastinal abscesses, and intrathoracic irrigation and drainage. The patient underwent a unilateral 
Table 2 Detailed characteristics and treatment of the patients

\begin{tabular}{|c|c|}
\hline Characteristics $(\mathrm{n}=6)$ & Median or number [range or \%] \\
\hline \multicolumn{2}{|l|}{ Initial antibiotics } \\
\hline Carbapenem & $4[67]$ \\
\hline Sulbactam and ampicillin & $2[33]$ \\
\hline \multicolumn{2}{|l|}{ Drainage } \\
\hline Cervical drainage & $6[100]$ \\
\hline Tracheotomy & $6[100]$ \\
\hline Thoracotomy & $6[100]$ \\
\hline Unilateral & $1[17]$ \\
\hline Appearance of pleural effusion in the opposite thorax & $1[17]$ \\
\hline Appearance of abscesses in thoracic cavity or cervical space & $2[33]$ \\
\hline Duration of hospitalization (days) & $58[34-126]$ \\
\hline Recurrence & 0 \\
\hline 90-day mortality & 0 \\
\hline Disease-associated death & 0 \\
\hline
\end{tabular}

approach for unilateral thoracic fluid collection; however, re-operation was performed 3 days after the first surgery because of the appearance of fluid collection in the opposite thoracic cavity (Figure 1). Two patients required additional debridement at day 8 (Figure 2) and day 10.

The median duration of hospitalization after surgery was 58 days (range, 34-126 days) and the median duration of hospitalization after surgery in patients with mixed infection including SAG was 82 days. In the median follow-up period of 18 months, no patients experienced a recurrence of infection after discharge or disease-associated death $(0 \%)$.

\section{Detailed analysis of prognosis}

Table 3 shows the detailed variables of the patients. In all patients where SAG was detected, there was a mixed aerobic and anaerobic infection, as well as presence of gas bubbles on imaging and sepsis on presentation. DIC was present in three out of four with SAG detected. Therefore, presence of SAG was associated with sepsis, DIC, and longer postoperative hospitalization.

\section{Discussion}

This study investigated additional factors associated with the aggressiveness and prognosis of diffuse DNM by analyzing cases of DNM with Endo classification type IIB surgically treated in a single institution. Based on the medias postsurgical hospitalization, polymicrobial infection including SAG, gas bubbles in the abscess on CT, and sepsis were all detected in patients with long hospitalization and may be factors for aggression in DNM.

Previous articles reported that the extent of the infection is a strong prognostic factor (3). The prognosis of DNM remains poor, with a mortality rate of $17.5 \%(3,4)$. The prognosis of DNM extending into the lower mediastinum (Endo classification type II) is even worse. Kocher et al. reviewed the literature up to the early 2000s and reported a significant difference in prognosis according to Endo classification (Type I vs. II =9\% vs. 34\%, $\mathrm{P}=0.005$ ) (18). Prado-Calleros et al. reviewed literature published from 2009 to 2014 and reported that $17.7 \%$ of patients with Endo type II classification died, compared to $6.9 \%$ of patients with type I classification (3). Furthermore, the prognosis of 

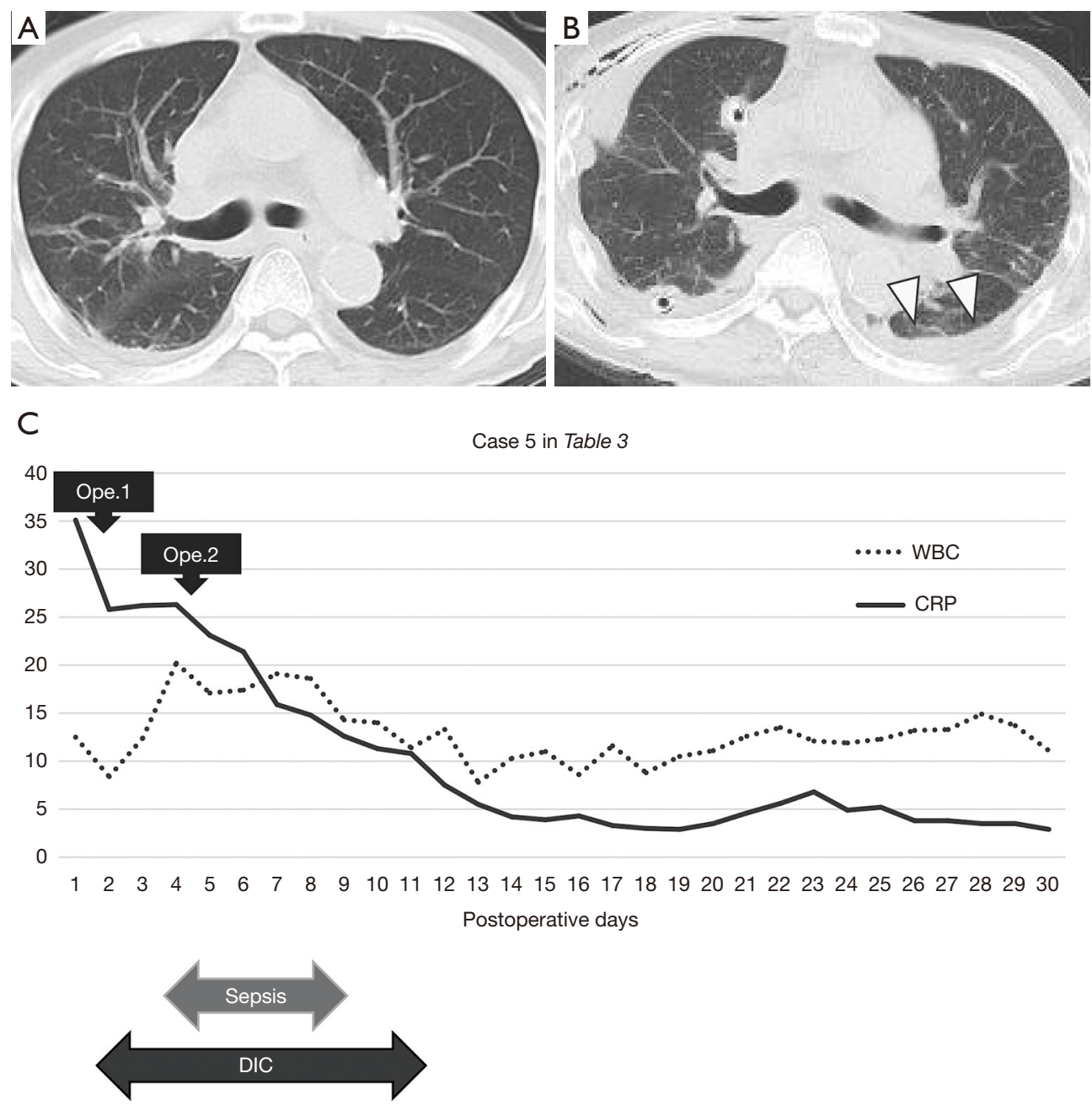

Figure 1 Computed tomography scan (A) before surgery and (B) at 3 days after the initial surgery, and (C) trend graph of white blood cells and C-reactive protein of Case 5 in Table 3. Debridement and irrigation for the mediastinum and right thorax were performed via a right-sided thoracoscopic approach; however, the general condition and blood test were not improved enough, and CT scan revealed the appearance of pleural effusion of the opposite thorax (arrows) (B) not observed before surgery (A). Additional debridement and irrigation for the mediastinum and left thorax improved the patient's condition (C). WBC, white blood cell; CRP, C-reactive protein; DIC, disseminated intravascular coagulation.

diffuse DNM extending to both the anterior and posterior mediastinum inferior to the carina (Endo classification: type IIB) was worse than that for type IIA (19). Some articles also reported the relationship between the inflection site and DNM (20), and that the presence of comorbidities and complications, with higher mortality or modality rates observed in patients with comorbidities including diabetes mellitus (21) as well as those with sepsis and septic shock (22). The relationship between the infection site, comorbidities, and initial antibiotics, and aggravation and prognosis of DNM could not be proved in our study, further analyses may clarify the risk factor.

As mentioned above, the prognostic factors of DNM have been gradually clarified and a treatment strategy has been formulated. However, efficient prognostic analysis including causative bacteria has not yet been reported. DNM is frequently caused by polymicrobial infections (3), with Streptococcus group and Bacteroides species the most commonly detected causative bacteria (19). Within the Streptococcus group, SAG is particularly reported as the causative bacteria of respiratory infections involving the mechanism of aspiration, especially intrathoracic 

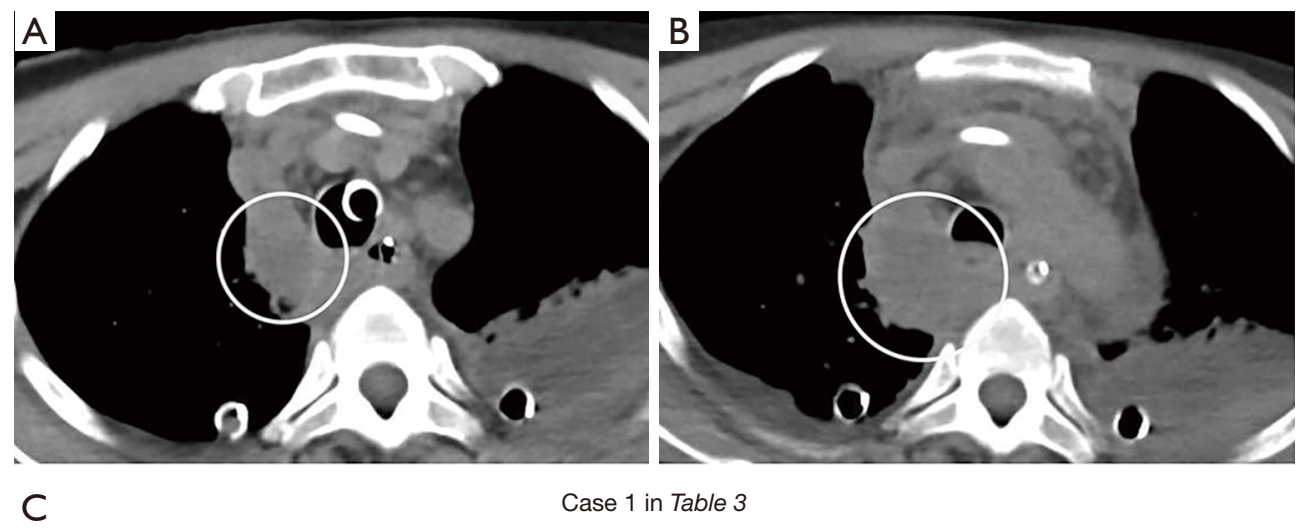

Case 1 in Table 3

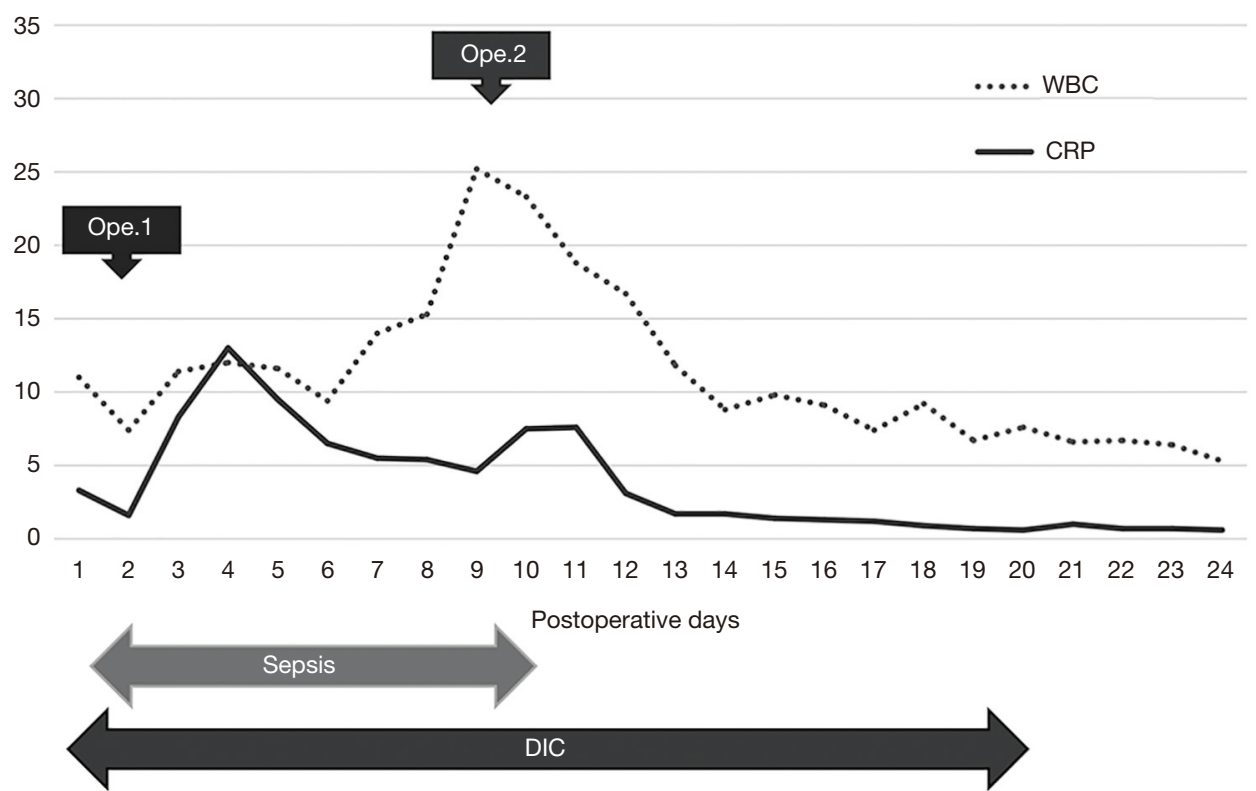

Figure 2 Computed tomography scan (A) before surgery and (B) at 8 days after the initial surgery, and (C) trend graph of white blood cells and C-reactive protein of Case 1 in Table 3. Debridement and irrigation for the mediastinum and bilateral thorax were performed via the bilateral thoracoscopic approach; however, exacerbation of blood test was observed and CT scan revealed an increase in the insufficient drainage area in the right mediastinum (circle) (B) not observed just after the surgery (circle) (A). Additional debridement and irrigation for the right thorax improved the patient's condition (C). WBC, white blood cell; CRP, C-reactive protein; DIC, disseminated intravascular coagulation.

abscesses and empyema (23-25). SAG, previously called the Streptococcus milleri group, is a resident bacteria of the oral and upper respiratory tracts (26). As SAG is microaerophilic bacteria and slowly grows in culture, reports of SAG have recently increased due to advances in culture technology $(27,28)$. Although there had been few studies reporting SAG as the causative bacteria of DNM (25), in their analysis of the predictors of cervical necrotizing fasciitis descending to the mediastinum, Petitpas et al. reported that SAG and anaerobic bacteria were detected most frequently, at 57\% and $65 \%$, respectively. Petitpas et al. also reported gas bubbles on a chest CT scan as an independent risk factor for mediastinal spread from cervical necrotizing fasciitis (29). Gas bubbles in the abscess on CT may suggest mixed polymicrobial aerobic and anaerobic bacterial infections.

Okada $e t$ al. reported that pleural effusion was detected more often in patients with SAG infections than in those with other bacterial infections (30). Mixed polymicrobial aerobic and anaerobic bacteria facilitate the lowering of the redox potential of closed spaces and the establishment of necrotic infection by anaerobic bacteria $(1,31,32)$. Mixed infections reported with SAG indicates that the 
Table 3 Detailed variables of the patients

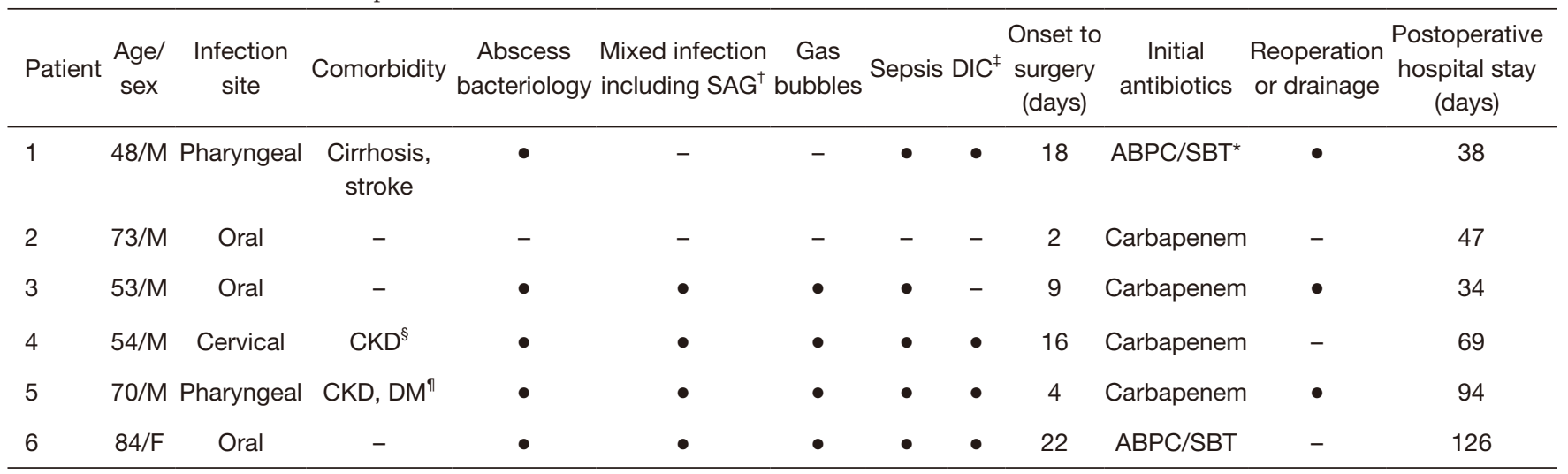

${ }^{\dagger} \mathrm{SAG}$, Streptococcus anginosus group; ${ }^{\ddagger} \mathrm{DIC}$, disseminated intravascular coagulation; ${ }^{\S} \mathrm{CKD}$, chronic kidney disease; "DM, diabetes mellitus; *ABPC/SBT, sulbactam and ampicillin; •, observed.

disease progresses rapidly and synergistically exacerbates inflammation $(23,33)$. In the present study, we detected polymicrobial infections with SAG and anaerobic bacteria in $67 \%$ (4 of 6) of the cases of patients with diffuse DNM (Endo type IIB), all of which were complicated with bilateral empyema. The detection of SAG in the abscess of the DNM patients may be a risk factor for the spread of the infection to the inferior mediastinum and the thoracic cavity and longer hospital stay.

As the detection of SAG in the DNM abscess may be a risk factor for the spread of the infection to the inferior mediastinum and thoracic cavity, special attention to the potential for rapid deterioration should be paid when SAG is detected.

\section{Study limitations}

This study is a single-center retrospective analysis and included a small number of cases. DNM is a relatively rare disease and only small-sized retrospective studies and reviews have been published previously. As DNM includes various patient characteristics, causative bacteria and diseases, and extents of inflammation, a unified treatment strategy should be planned and multi-center prospective analyses may improve patient prognosis.

\section{Acknowledgments}

Funding: None.

\section{Footnote}

Reporting Checklist: The authors have completed the STROBE reporting checklist. Available at http://dx.doi. org/10.21037/apm-20-2120

Data Sharing Statement: Available at http://dx.doi. org/10.21037/apm-20-2120

Peer Review File: Available at http://dx.doi.org/10.21037/ apm-20-2120

Conflicts of Interest: All authors have completed the ICMJE uniform disclosure form (available at http://dx.doi. org/10.21037/apm-20-2120). The authors have no conflicts of interest to declare.

Ethical Statement: The authors are accountable for all aspects of the work in ensuring that questions related to the accuracy or integrity of any part of the work are appropriately investigated and resolved. The study was conducted in accordance with the Declaration of Helsinki (as revised in 2013). The study was approved by institutional ethics board of Toho University Omori Medical Center (No. M19218) and individual consent for this retrospective analysis was waived.

Open Access Statement: This is an Open Access article distributed in accordance with the Creative Commons 
Attribution-NonCommercial-NoDerivs 4.0 International License (CC BY-NC-ND 4.0), which permits the noncommercial replication and distribution of the article with the strict proviso that no changes or edits are made and the original work is properly cited (including links to both the formal publication through the relevant DOI and the license). See: https://creativecommons.org/licenses/by-nc-nd/4.0/.

\section{References}

1. Estrera AS, Landay MJ, Grisham JM, et al. Descending necrotizing mediastinitis. Surg Gynecol Obstet 1983;157:545-52.

2. Freeman RK, Vallières E, Verrier ED, et al. Descending necrotizing mediastinitis: An analysis of the effects of serial surgical debridement on patient mortality. J Thorac Cardiovasc Surg 2000;119:260-7.

3. Prado-Calleros HM, Jiménez-Fuentes E, Jiménez-Escobar I. Descending necrotizing mediastinitis: Systematic review on its treatment in the last 6 years, 75 years after its description. Head Neck 2016;38 Suppl 1:E2275-83.

4. Hassanein AG, Mohamed EEH, Hazem M, et al. Assessment of prognosis in odontogenic descending necrotizing mediastinitis: A longitudinal retrospective study. Surg Infect (Larchmt) 2020.

5. Wheatley MJ, Stirling MC, Kirsh MM, et al. Descending necrotizing mediastinitis: Transcervical drainage is not enough. Ann Thorac Surg 1990;49:780-4.

6. Marty-Ane CH, Alauzen M, Alric P, et al. Descending necrotizing mediastinitis. advantage of mediastinal drainage with thoracotomy. J Thorac Cardiovasc Surg 1994;107:55-61.

7. Iyoda A, Yusa T, Fujisawa T, et al. Descending necrotizing mediastinitis: Report of a case. Surg Today 1999; 29:1209-12.

8. Iwata T, Sekine Y, Shibuya K, et al. Early open thoracotomy and mediastinopleural irrigation for severe descending necrotizing mediastinitis. Eur J Cardiothorac Surg 2005;28:384-8.

9. Endo S, Murayama F, Hasegawa T, et al. Guideline of surgical management based on diffusion of descending necrotizing mediastinitis. Jpn J Thorac Cardiovasc Surg 1999;47:14-9.

10. Guan X, Zhang WJ, Liang X, et al. Optimal surgical options for descending necrotizing mediastinitis of the anterior mediastinum. Cell Biochem Biophys 2014;70:109-14.

11. Hsin MKY, Yim APC. Video assisted thoracoscopic surgery is a valuable approach for the management of descending necrotizing mediastinitis. Ann Surg 2011;253:1055; author reply 1055-6.

12. Abu-Omar Y, Kocher GJ, Bosco P, et al. European association for cardio-thoracic surgery expert consensus statement on the prevention and management of mediastinitis. Eur J Cardiothorac Surg 2017;51:10-29.

13. Kobayashi N, Maekawa T, Takada M, et al. Criteria for diagnosis of DIC based on the analysis of clinical and laboratory findings in 345 DIC patients collected by the Research Committee on DIC in Japan. Bibl Haematol 1983;(49):265-75.

14. American College of Chest Physicians/Society of Critical Care Medicine Consensus Conference: definitions for sepsis and organ failure and guidelines for the use of innovative therapies in sepsis. Crit Care Med 1992;20:864-74.

15. Bone RC, Balk RA, Cerra FB, et al. Definitions for sepsis and organ failure and guidelines for the use of innovative therapies in sepsis. The ACCP/SCCM Consensus Conference Committee. American College of Chest Physicians/Society of Critical Care Medicine. Chest 1992;101:1644-55.

16. Vincent JL, Moreno R, Takala J, et al. The SOFA (sepsisrelated organ failure assessment) score to describe organ dysfunction/failure. On behalf of the working group on sepsis-related problems of the European society of intensive care medicine. Intensive Care Med 1996;22:707-10.

17. Singer M, Deutschman CS, Seymour CW, et al. The third international consensus definitions for sepsis and septic shock (sepsis-3). JAMA 2016;315:801-10.

18. Kocher GJ, Hoksch B, Caversaccio M, et al. Diffuse descending necrotizing mediastinitis: Surgical therapy and outcome in a single-centre series. Eur J Cardiothorac Surg 2012;42:e66-72.

19. Palma DM, Giuliano S, Cracchiolo AN, et al. Clinical features and outcome of patients with descending necrotizing mediastinitis: Prospective analysis of 34 cases. Infection 2016;44:77-84.

20. Qu L, Xu H, Liang X, et al. A retrospective cohort study of risk factors for descending necrotizing mediastinitis caused by multispace infection in the maxillofacial region. J Oral Maxillofac Surg 2020;78:386-93.

21. Bross-Soriano D, Arrieta-Gómez JR, Prado-Calleros H, et al. Management of ludwig's angina with small neck incisions: 18 years experience. Otolaryngol Head Neck Surg 2004;130:712-7. 
22. Dajer-Fadel WL, Ibarra-Pérez C, Sánchez-Velázquez LD, et al. Descending necrotizing mediastinitis below the tracheal carina. Asian Cardiovasc Thorac Ann 2014;22:176-82.

23. Shinzato T, Saito A. The streptococcus milleri group as a cause of pulmonary infections. Clin Infect Dis 1995;21 Suppl 3:S238-43.

24. Noguchi S, Yatera K, Kawanami T, et al. The clinical features of respiratory infections caused by the streptococcus anginosus group. BMC Pulm Med 2015;15:133.

25. Ye RH, Yang JC, Hong HH, et al. Descending necrotizing mediastinitis caused by streptococcus constellatus in an immunocompetent patient: Case report and review of the literature. BMC Pulm Med 2020;20:43.

26. Wong CA, Donald F, Macfarlane JT. Streptococcus milleri pulmonary disease: A review and clinical description of 25 patients. Thorax 1995;50:1093-6.

27. Bert F, Bariou-Lancelin M, Lambert-Zechovsky N. Clinical significance of bacteremia involving the "streptococcus milleri" group: 51 cases and review. Clin

Cite this article as: Sakai T, Sano A, Azuma Y, Koezuka S, Otsuka H, Iyoda A. Streptococcus anginosus group infection as a predictor for the progression of descending necrotizing mediastinitis. Ann Palliat Med 2021;10(4):4008-4016. doi: 10.21037/ apm-20-2120
Infect Dis 1998;27:385-7.

28. Limia A, Jiménez ML, Alarcón T, et al. Five-year analysis of antimicrobial susceptibility of the streptococcus milleri group. Eur J Clin Microbiol Infect Dis 1999;18:440-4.

29. Petitpas F, Blancal J, Mateo J, et al. Factors associated with the mediastinal spread of cervical necrotizing fasciitis. Ann Thorac Surg 2012;93:234-8.

30. Okada F, Ono A, Ando Y, et al. High-resolution CT findings in streptococcus milleri pulmonary infection. Clin Radiol 2013 Jun;68:e331-7.

31. Stone HH, Martin JD. Synergistic necrotizing cellulitis. Ann Surg 1972;175:702-11.

32. Economopoulos GC, Scherzer HH, Gryboski WA. Successful management of mediastinitis, pleural empyema, and aortopulmonary fistula from odontogenic infection. Ann Thorac Surg 1983;35:184-7.

33. Shinzato T, Saito A. A mechanism of pathogenicity of "streptococcus milleri group" in pulmonary infection: Synergy with an anaerobe. J Med Microbiol 1994;40:118-23. 